\title{
Epigenética del cáncer colorrectal
}

\section{Epigenetics of Colorectal Cancer}

Carlos Humberto Afanador A., ${ }^{1}$ Carlos Mario Muñetón Peña. ${ }^{1}$

\author{
Unidad de genética médica, Departamento de \\ Pediatría, Facultad de Medicina; Universidad de \\ Antioquia, Medellín, Colombia. \\ Correspondencia: Carlos Mario Muñetón. \\ Correo: cmuneton@gmail.com; \\ carlos.muneton@udea.edu.co. \\ Fecha recibido: $15-05-17$ \\ Fecha aceptado: 22-01-18
}

\begin{abstract}
Resumen
El cáncer colorrectal (CCR) es una enfermedad con una amplia distribución geográfica, que afecta a millones de personas en el mundo. Esta neoplasia se presenta de manera esporádica en el $80 \%$ de los casos, el porcentaje restante tiene una historia familiar. Las alteraciones epigenéticas, como la metilación del ADN, modificación de las histonas y los ácidos ribonucleicos (ARN) no codificantes, están involucradas en el desarrollo de esta enfermedad. En la actualidad, estas alteraciones tienen un potencial valioso como biomarcadores para la detección temprana del CCR y se considera que podrían ser útiles para el diagnóstico y pronóstico de los individuos con CCR. El propósito de esta revisión es describir los principales mecanismos epigenéticos involucrados en el cáncer colorrectal, que tienen una función importante en el desarrollo y progresión de la enfermedad.
\end{abstract}

\section{Palabras clave}

Cáncer colorrectal, epigenética, metilación del ADN, genes de reparación, genes supresores de tumor.

\section{Abstract}

Colorectal cancer (CRC) has broad geographic distribution and affects millions of people throughout the world. It occurs sporadically in $80 \%$ of cases, but the rest have family histories. Epigenetic alterations such as DNA methylation and modification of histones and non-coding RNA are involved in the development of this disease. At present, these alterations have valuable potential as biomarkers for early detection of CRC and could be useful for diagnosis and determination of prognosis for individuals with CRC. The purpose of this review is to describe the main epigenetic mechanisms involved in colorectal cancer and the important roles they have in the development and progression of the disease.

\section{Keywords}

Colorectal cancer, epigenetics, DNA methylation, repair genes, tumor suppressor genes.

\section{INTRODUCCIÓN}

El cáncer colorrectal (CCR) se considera un problema de salud pública con una amplia distribución geográfica, según el registro de GLOBOCAN 2012 (1). Actualmente, el CCR es el tercer cáncer más común en hombres y mujeres en el mundo, con una alta tasa de incidencia en países desarrollados (1); por el contrario, los países en vía de desa- rrollo tienen una baja incidencia (2). Sin embargo, datos recientes de la Agencia Internacional de Investigaciones del Cáncer (IARC) muestran un aumento en las tasas de incidencia y mortalidad en países menos desarrollados $(3,4)$.

En Colombia, se reporta un aumento de las tasas de incidencia y mortalidad del CCR durante las últimas décadas $(5,6)$. De acuerdo con las cifras de GLOBOCAN 2012 para Colombia, el CCR ocupa el cuarto lugar en inciden- 
cia y mortalidad en ambos sexos; al año se presentan 4107 nuevos casos, la mayoría diagnosticados en estados avanzados de la enfermedad (1).

El CCR ocurre de forma esporádica en cerca del $80 \%$ y el 20\% restante tiene una historia familiar; las mutaciones germinales en los genes APC y MLH1 predisponen al CCR de tipo hereditario (7-9). El CCR se origina por diferentes alteraciones genéticas que están involucradas en el inicio y desarrollo de esta enfermedad (10); dichas alteraciones afectan la expresión de múltiples genes, promoviendo la trasformación de la mucosa normal del colon hacia un pólipo benigno, que progresa hacia un adenoma temprano, luego se vuelve intermedio hasta, finalmente, avanzar a un adenocarcinoma de colon (10).

Por una parte, se conocen diferentes vías moleculares para explicar el desarrollo del CCR. Inicialmente, se propuso el modelo clásico de progresión de adenoma hacia carcinoma por Fearon y Vogelstein (11) que se denomina vía tradicional o supresora, e involucra la inactivación de los genes supresores de tumores APC y TP53, y mutaciones en los oncogenes KRAS, DCC y SMAD (11). La segunda vía se denomina mutadora y se relaciona con mutaciones en los genes del sistema de reparación MMR, principalmente MLH1 y MSH2, que inducen inestabilidad microsatelital (MSI, microsatellite instability) en las células tumorales (12). La tercera vía implicada en el desarrollo del CCR es la epigenética, que consiste en la represión de la expresión génica mediante la metilación de la región promotora de los genes supresores tumorales o de reparación (13).

Por otra parte, el término epigenética se estableció en 1942 por Conrad Hal Waddington para describir los mecanismos que modifican la estructura de la cromática y afectan los niveles de la expresión de genes, sin cambios en la secuencia de ácido desoxirribonucleico (ADN); estos mecanismos incluyen la metilación, acetilación e hidroxilación del $\mathrm{ADN}$, modificación de proteínas tipo histonas y la remodelación de la estructura de la cromatina; así como los ácidos ribonucleicos (ARN) no codificantes o micro-ARN. Las modificaciones epigenéticas se pueden inducir por factores externos e internos que podrían tener efectos similares a los de las mutaciones patogénicas, puesto que podrían inactivar la expresión de diversos genes en un determinado tejido; lo anterior se ha evidenciado en la carcinogénesis de diferentes órganos y tiene gran importancia en el desarrollo del cáncer, teniendo en cuenta que estas modificaciones afectan la expresión de genes supresores de tumores o genes del sistema de reparación del ADN (14).

El propósito de esta revisión es describir las principales modificaciones epigenéticas relacionadas con el CCR y su importancia en las aplicaciones clínicas que podrían ser utilizadas como biomarcadores para la detección temprana del CCR.

\section{MODIFICACIÓN DE LAS HISTONAS}

Un mecanismo por el que se induce un control transcripcional sobre la expresión de los genes involucra modificaciones en las proteínas histonas que están asociadas con el $\operatorname{ADN}(15,16)$. Se conoce que las modificaciones covalentes postraduccionales en regiones específicas de las histonas constituyen un mecanismo epigenético que regula y modifica la estructura de la cromatina; por lo anterior, se considera que dichas modificaciones podrían estar asociadas con el origen y progresión del cáncer (16).

El entendimiento de las modificaciones de las histonas en el desarrollo del cáncer en humanos hasta el presente es muy limitado. Las modificaciones en las histonas ocurren comúnmente en $\mathrm{H} 2 \mathrm{~A}, \mathrm{H} 2 \mathrm{~B}, \mathrm{H} 3$ y H4, las cuales hacen parte del octámero de histonas y están organizadas en una estructura cilíndrica $(15,16)$. El nucleosoma es una unidad compuesta de aproximadamente 150 a 200 pares de bases de $\mathrm{ADN}$ que se disponen alrededor de las histonas nucleosómicas; la porción $\mathrm{N}$-terminal de cada histona que emerge de esta estructura compacta es el blanco en las que ocurren las modificaciones postraduccionales. Los principales tipos de modificaciones son la fosfoliración, glucosilación, ADPribosilación, ubiquitinación, sumoilación y, las más comunes, acetilación y metilación (Figura 1) $(15,16)$.

La acetilación y la metilación son las modificaciones epigenéticas más estudiadas en el cáncer. Se ha observado que los residuos de aminoácidos, el tipo de modificaciones y dominio de la histona están asociados con el desarrollo y progresión del cáncer (16-18). En general, dentro de los mecanismos epigenéticos, las modificaciones de las histonas son de gran importancia y objeto de muchos estudios en la epigenética del cáncer.

Los estados de acetilación/desacetilación y metilación/ desmetilación de los residuos de lisina y arginina en las histonas están entre las modificaciones más estudiadas y entendidas. En general, se conoce que la hipoacetilación reprime la expresión génica; mientras que la hiperacetilación de las histonas activa la transcripción de los genes. La acetilación en motivos específicos de las histonas desestabiliza la fibra de cromatina, lo que permite un aumento de la movilidad de los nucleosomas en los cromosomas y, en este estado, se unen los factores de transcripción al ADN (19).

Actualmente, se conoce que la desacetilación de la histona $\mathrm{H} 3 \mathrm{~K} 9$ se relaciona con la represión de la transcripción de la E-cadherina en células de tumores colorrectales; otros estudios informan que la pérdida de la expresión de la E-cadherina por metilación y la subsecuente pérdida de la adhesión celular parecen ser un paso crítico en la capacidad que adquieren las células tumorales para invadir tejidos adyacentes y llevar a cabo la metástasis. Diferentes estudios han demostrado que la expresión de esta proteína es nula 


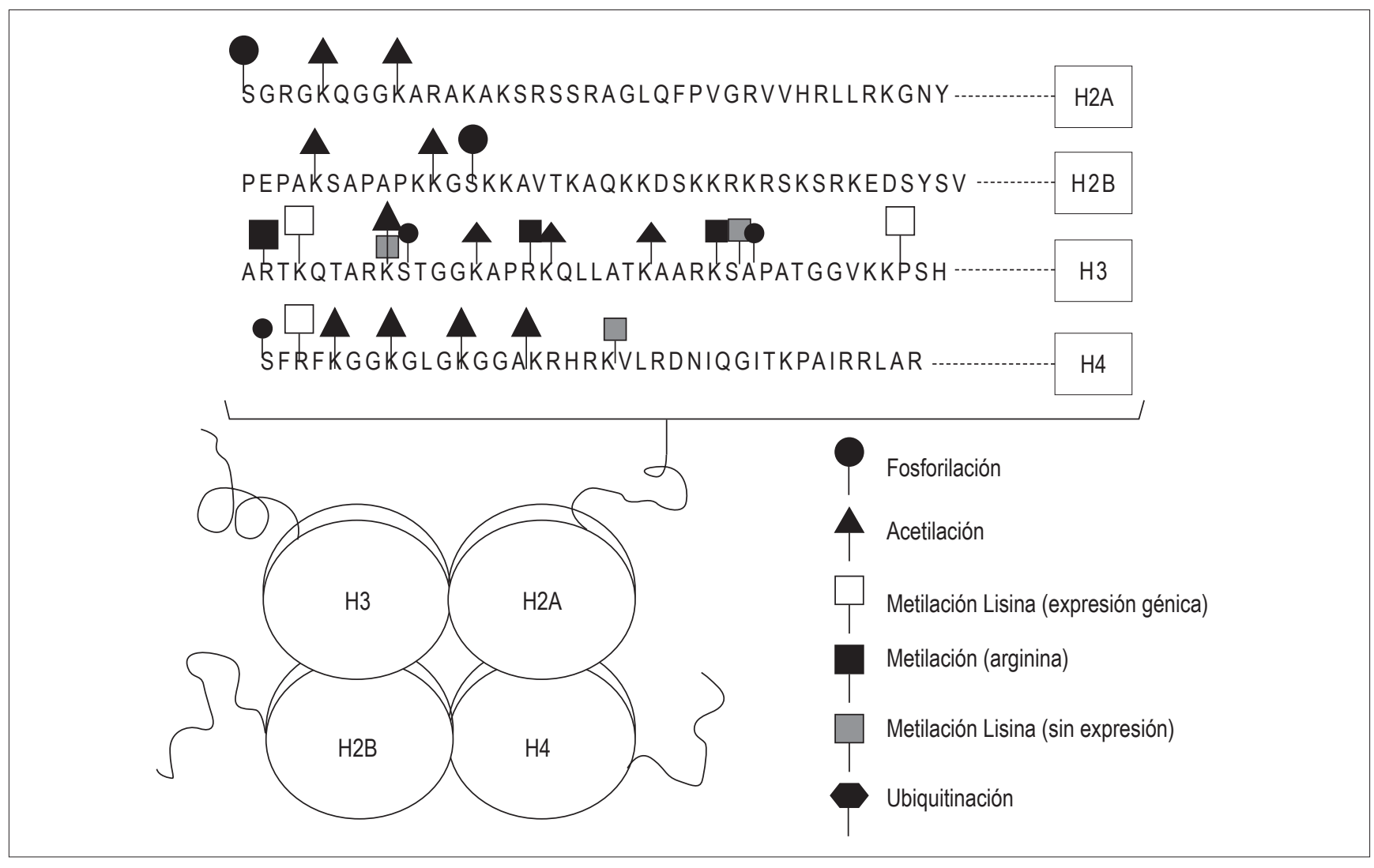

Figura 1. Principales modificaciones postraduccionales en los residuos $\mathrm{N}$-terminales de las histonas. Las 4 proteínas histonas (H2A, H2B, H3 y H4) tienen una estructura cilíndrica denominada núcleo histónico. Las principales modificaciones covalentes de cada histona son la fosfoliración, acetilación, metilación y ubiquitinación. En la imagen se observa la secuencia de aminoácidos que componen el residuo N-terminal de cada histona y el sitio donde ocurre cada tipo de modificación.

o muy escasa en carcinomas poco diferenciados, incluidos los de CCR $(20,21)$.

\section{METILACIÓN DEL ADN}

La regulación de la expresión génica es el producto de la interacción entre los factores de inicio de la transcripción y las secuencias promotoras ubicadas antes del codón de inicio (ATG). En células normales, el 60\% de los genes codificantes en humanos, la región promotora es rica en secuencias de citosina-guanina (C-G, denominadas islas $C p G$ ) (22).

Un mecanismo por el que la célula puede inhibir completamente la expresión génica es evitar la unión de los factores de transcripción a secuencias reguladoras del $\mathrm{ADN}$ mediante la metilación de las regiones promotoras, específicamente en las islas $\mathrm{CpG}$, por la unión covalente de un grupo metilo $(\mathrm{CH} 3)$ en el carbono 5' de la citosina por medio de las enzimas ADN metiltransferasas (DNMT) (Figura 2); las islas CpG comprenden regiones entre $200 \mathrm{y}$ 2000 pares de bases con una proporción de CG >50\% (23).
La metilación reprime la transcripción por la unión de proteínas ligadoras de metil-CpG (MBP) que interactúan con las secuencias $\mathrm{CpG}$ metiladas, lo que impide la unión de los factores de transcripción con secuencias de $\mathrm{ADN}$; esto produce la inactivación los de genes $(24,25)$. Es importante resaltar que las islas $\mathrm{CpG}$ que no están dentro de un gen activo se mantienen en su mayoría metiladas, mientras que las islas $\mathrm{CpG}$ que no se encuentran metiladas hacen parte de la región promotora de genes que se expresan constitutivamente (Figura 3) (10).

Entre las modificaciones que ocurren en el genoma, la metilación tiene funciones importantes como regular los procesos de replicación, transcripción, reparación del $\mathrm{ADN}$ y expresión génica, en general. Adicionalmente, esta modificación del $\mathrm{ADN}$ es necesaria para la inactivación permanente de determinadas regiones con genes que no se expresan después del desarrollo embrionario y para la inactivación del cromosoma $\mathrm{X}$; también es esencial para la coordinación de procesos transcripcionales durante el desarrollo embrionario y la diferenciación celular (10). 


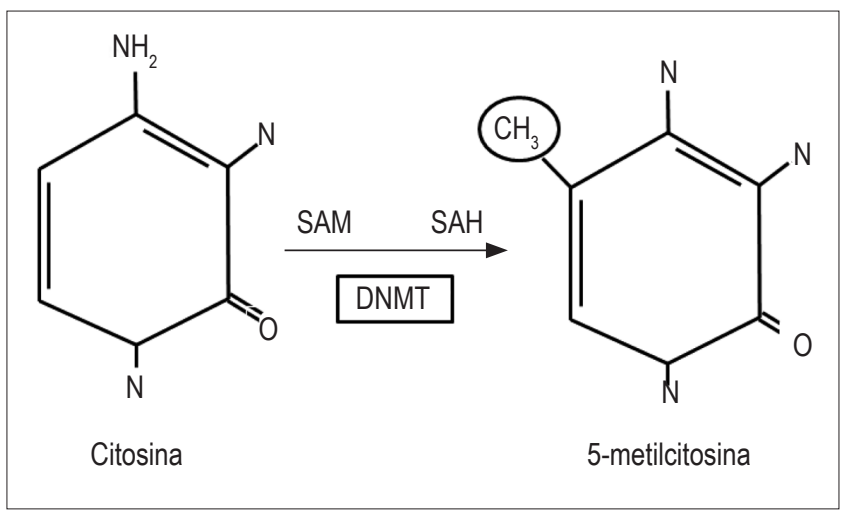

Figura 2. Metilación de la citosina en el carbono 5 mediante la enzima DNMT. Esta enzima cataliza la unión de un grupo metilo $\mathrm{CH}_{3}$ en el carbono 5 de la citosina, empleando como molécula donadora del grupo $\mathrm{CH}_{3}$ la S-adenosil metionina (SAH). SAH: S-adenosil L-homocisteína.

\section{HIPERMETILACIÓN DEL ADN EN EL CÁNCER COLORRECTAL}

La metilación del ADN se ha estudiado ampliamente en diferentes tipos de cáncer $(19,26,27)$. Asimismo, es bien conocida la asociación entre la hipermetilación en las islas CpG localizadas cerca de la región promotora de genes y la inactivación de la transcripción génica, incluyendo la represión de la transcripción de genes supresores de tumores, genes que regulan el ciclo celular y genes del sistema de reparación del $\mathrm{ADN}$ (28). Estos genes usualmente están involucrados en múltiples procesos biológicos importantes como: la proliferación celular, apoptosis, angiogénesis, invasión y adhesión celular (29).

Particularmente en el CCR, múltiples estudios han informado que es frecuente la hipermetilación de la región pro-

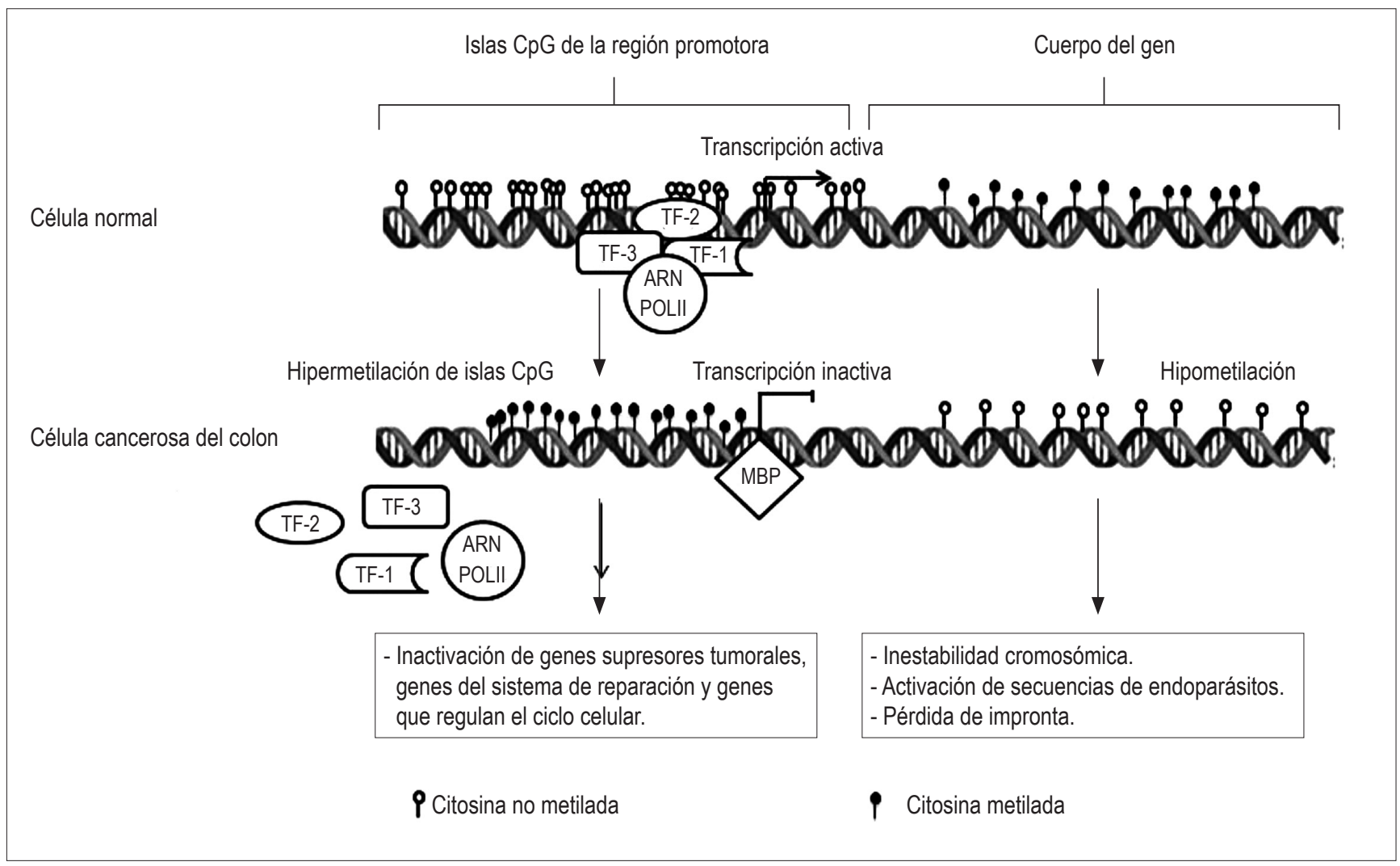

Figura 3. Estado de metilación del $\mathrm{ADN}$. En la región promotora de una célula normal del colon, las islas CpG dentro del promotor no se encuentran hipermetiladas (círculos en blanco), lo cual permite que se una el ARN polimerasa II (ARN POLII) y los factores de transcripción, como el FT-2, FT-3 y FT-1; de esta manera, se da la transcripción normal del gen. En contraste, en una célula de adenocarcinoma de colon, las islas CpG de la región promotora se encuentra hipermetilada (círculos negros); lo que reprime la transcripción por la unión de proteínas MBP que interactúan con las secuencias CpG metiladas; a su vez, esto impide la unión de los factores de transcripción con el ADN y, por tanto, se produce la inactivación génica. 
motora de los genes RB1, APC, MLH1, MGMT, CDH1, CDKN2A, RUNX3, y RASSF1A, entre muchos otros (Tabla 1) (26, 30-39).

Por una parte, uno de los primeros descubrimientos del efecto de la metilación en las islas $\mathrm{CpG}$ en un gen supresor de tumores en cáncer fue el del retinoblastoma (RB1), que se encuentra hipermetilado entre el 10\%-20\% de los casos de CCR. El RB1 codifica para una nucleoproteína que tiene una función importante en la regulación del ciclo celular; la pérdida de la función de este gen causa una proliferación celular incontrolada; este gen se encuentra alterado en una gran variedad de tumores, incluido el CCR (30).

Por otra parte, la hipermetilación del promotor del gen MLH1 se relaciona con el desarrollo de CCR esporádico y hereditario que presenta MSI (26). El gen MLH1 hace parte del sistema de reparación de bases mal apareadas (MMR, mismatch repair); los defectos en estos genes por mutaciones puntuales o por el silenciamiento epigenético son la causa de la MSI en el desarrollo del CCR (33). Este gen se encuentra metilado hasta en el $60 \%$ de los casos esporádicos de CCR (32). En algunos casos, se ha observado que el gen MLH1 está metilado en tejido adyacente al tumor con una apariencia morfológica normal, por lo que se propone como un biomarcador para la detección temprana del CCR; sin embargo, se requieren más estudios para establecer lo anterior $(31,32)$.

De manera similar, el gen MGMT, un gen del sistema de reparación del $\mathrm{ADN}$ encargado de remover aductos del $\mathrm{ADN}$ y prevenir la formación de MMR, se encuentra hipermetilado en el 38\% de los pólipos colorrectales; en estos casos, se asocia la inactivación de este gen con el desarrollo CCR y con mutaciones en otros genes involucrados en este tipo de cáncer como APC, KRAS Y TP53 (34).
Asimismo, estudios de metilación en el gen supresor de tumores $\mathrm{CDH} 1$ han mostrado que este gen está hipermetilado en el 46\% de los casos de CCR (35); como consecuencia de esta modificación epigenética, se disminuyen la expresión y la función de la proteína E-cadherina, favoreciendo de esta manera un aumento en la proliferación celular, la invasión y la metástasis de las células tumorales de colon. También la inactivación de este gen podría asociarse con alteraciones de otros genes importantes en el desarrollo de CCR, como es el caso del gen APC (35).

Por su parte, el gen CDKN2A (p16), otro supresor de tumores, se encuentra hipermetilado en el $30 \%$ de los casos con CCR. La represión transcripcional de este gen también favorece el desarrollo, progresión e invasión de las células transformadas en este tipo de cáncer. Adicionalmente, esta modificación se encuentra con frecuencia en el colon ascendente y se asocia con un mal pronóstico en los pacientes con esta enfermedad (36).

Otra de las evidencias de la inactivación epigenética en CCR ocurre con el gen RUNX3, que actúa como supresor de tumores en el epitelio del colon. Su inactivación se presenta aproximadamente en el $20 \%$ de los casos de CCR (37). De estos resultados, se propone una asociación significativa entre la inactivación de RUNX3 y CCR con MSI positiva; se concluye que el gen RUNX3 es importante en el desarrollo de CCR $(37,38)$.

El gen RASSF1A se encuentra comúnmente hipermetilado en el CCR, es un gen supresor de tumores que actúa en la progresión de la fase G1 hacia la S del ciclo celular (39, 40). La metilación de este gen se observa en el $47 \%$ de los casos de CCR, con un estado avanzado de la enfermedad, con metástasis e invasión linfática. Asimismo, se propone una correlación significativa entre los casos de CCR con

Tabla 1. Principales genes hipermetilados en CCR. Se presenta una lista de diversos genes frecuentemente metilados en CCR, la función y la técnica empleada del análisis epigenético.

\begin{tabular}{|c|c|c|c|c|c|}
\hline Gen & Nombre & Función & Metilación (\%) & Técnica & Referencia \\
\hline RB1 & Retinoblastoma & Supresor de tumores & $10-20$ & MSP (PCR) & $(30)$ \\
\hline MLH1 & MutL Homolog 1 & Sistema de reparación del ADN & 60 & MSP (PCR) & $(26,32)$ \\
\hline MGMT & 06-metilguanina-ADN-metiltransferasa & Sistema de reparación del ADN & 38 & MethyLight & $(34)$ \\
\hline $\mathrm{CDH} 1$ & E-cadherina & Supresor de tumores & 46 & MSP (PCR) & $(35)$ \\
\hline CDKN2A & Inhibidor de cinasa dependiente de ciclina 2A & Supresor de tumores & 30 & $\begin{array}{l}\text { Pirosecuenciación, } \\
\text { MSP (PCR) }\end{array}$ & $(36)$ \\
\hline RUNX3 & Factor de transcripción relacionado con Runt & Supresor de tumores & 29 & MSP (PCR) & $(37,38)$ \\
\hline RASSF1A & Ras association domain family 1 isoform $A$ & Supresor de tumores & 47 & MSP (PCR) & $(39)$ \\
\hline
\end{tabular}

MSP: methylation-specific PCR; PCR: reacción en cadena de la polimerasa. 
mutación en el codón 12 de gen KRAS y el estado de hipermetilación de este gen, por lo que se sugiere que, además de considerarse importante en el desarrollo del CCR, también podría ser útil como un biomarcador de metilación en este tipo de cáncer (39).

\section{LA HIPERMETILACIÓN DEL ADN COMO MARCADOR DIAGNÓSTICO EN EL CÁNCER COLORRECTAL}

Los mecanismos de hipermetilación descritos anteriormente sugieren que la metilación de determinados genes podría considerarse, en algunos casos, como un evento previo a la aparición del tumor; por tanto, la detección del estado de metilación en el epitelio y en lesiones premalignas, así como en otros tipos de muestras biológicas (sangre o heces), podría utilizarse como un biomarcador de detección temprana para el diagnóstico preventivo y el pronóstico de los pacientes con CCR.

La hipermetilación se ha estudiado como un marcador epigenético en muchos tipos de neoplasias $(27,41,42)$. Por una parte, la aplicación de las técnicas para el análisis de la metilación del $\mathrm{ADN}$ para propósitos de diagnóstico podría presentar varias ventajas cuando se compara con otros biomarcadores conocidos, tales como mutaciones puntuales o perfiles de expresión génica. En primer lugar, las alteraciones en los patrones de la metilación del $\mathrm{ADN}$ se encuentran en regiones del genoma bien definidas: las islas $\mathrm{CpG}$, y pueden detectarse por diferentes técnicas muy específicas y sensibles; adicionalmente, es importante mencionar que algunas de estas técnicas son económicas (39). En segundo lugar, la posibilidad de realizar el análisis de estos biomarcadores de metilación en sangre periférica y en heces permite evaluar individuos mediante métodos menos invasivos. Por otra parte, la estabilidad del ADN hace posible el análisis de estos biomarcadores en tejidos incluidos en parafina, lo que permite realizar estudios retrospectivos a partir de archivos patológicos de tumores (41).

De acuerdo con lo anterior, la metilación del gen SEPT9 se ha observado en más del $90 \%$ de los pacientes con CCR; este es el único biomarcador epigenético aprobado por la Food and Drug Administration (FDA) disponible como una prueba diagnóstica para la detección temprana del CCR $(43,44)$. La detección de SEPT9 metilado en sangre se asocia con un adenocarcinoma colorrectal; en individuos con resultado positivo para esta prueba, se debe recomendar la colonoscopia para confirmar el diagnóstico de CCR. La prueba de metilación de SEPT9 tiene una alta sensibilidad y especificidad, lo que representa una gran ventaja para la detección temprana de CCR (45). Esta prueba se ofrece rutinariamente a los individuos con alto riesgo de CCR en algunos países desarrollados (45). Adicionalmente, también se ha sugerido que el análisis del estado de metila- ción en muestras de sangre periférica de genes como APC, MLH1, MGMT, CDKN2A y RASSF2A podría ser importante para la detección temprana de CCR (46).

Los biomarcadores epigenéticos descritos, además de tener una importante utilidad en la detección temprana de CCR, podrían ser muy benéficos en el estudio de individuos con un alto riesgo de desarrollar CCR, ya que a estos se les podría recomendar anticipadamente pruebas diagnósticas, intervenciones quirúrgicas o terapias farmacológicas más específicas frente a la naturaleza reversible de las modificaciones epigenéticas (47). Sin embargo, se requieren más estudios que validen las pruebas de los marcadores epigenéticos en el diagnóstico y pronóstico de los pacientes con CCR.

\section{FENOTIPO METILADOR DE ISLAS CPG (CIMP) EN CÁNCER COLORRECTAL}

El concepto de CIMP (o island methylator phenotype) fue propuesto por Toyota y colaboradores, quienes sugirieron que el CCR se podría clasificar en 2 categorías: una de baja metilación (menos de 2 genes metilados), denominada $C I M P$-, y otra que exhibe una alta metilación en más de 2 genes simultáneamente o CIMP+ (48).

Los anteriores autores seleccionaron 5 genes para evaluar el estado CIMP en muestras de CCR: CDKN2A, MINT1, MINT2, MINT31 y MLH1; los cuales son útiles para definir subgrupos de CIMP (49). Además, otros autores han propuesto distintos paneles con un número mayor de marcadores para determinar el estado CIMP como son CACNA1G, CRABP1, IGF2, NEUROG1, RUNX3, SOCS1, HIC1, IGFBP y WR; sin embargo, no existe un consenso sobre cuáles y cuántos genes podría utilizarse para lograr una clasificación adecuada del CIMP en los pacientes con CCR (49-53).

De acuerdo con el análisis de un amplio panel de marcadores de metilación en CCR, se propuso que el CIMP podría dividirse en 2 categorías: CIMP1 y CIMP2 (51). Los tumores CIMP1 presentan MSI positiva y se correlaciona con mutaciones en el gen BRAF, mientras que los tumores CIMP2 presentan mutaciones en el gen KRAS y baja frecuencia de mutaciones en TP53, BRAF y MSI negativa (52). Por lo anterior, es de gran importancia resaltar la utilidad de los análisis de metilación en los pacientes con CCR, ya que se tendría la posibilidad de realizar una clasificación molecular más precisa de estos pacientes de acuerdo con sus perfiles de metilación.

\section{TERAPIA EPIGENÉTICA EN CÁNCER COLORRECTAL}

El análisis de la metilación en la región promotora de diversos genes podría proporcionar un marcador pronóstico de la progresión de la enfermedad, así como también de la 
respuesta a determinados tratamientos antineoplásicos. De esta forma, se ha observado que los marcadores epigenéticos específicos en CCR se asocian con un mal pronóstico. Asimismo, los marcadores epigenéticos han estado en constante investigación debido a la utilidad clínica que tendrían para predecir la respuesta de los pacientes a determinados medicamentos antineoplásicos $(10,53)$.

A diferencia de otras alteraciones moleculares involucradas en el inicio y progresión del CCR como mutaciones y la pérdida alélica, las alteraciones epigenéticas son potencialmente reversibles. Esta característica ha permitido el desarrollo de nuevas terapias basadas en restablecer la actividad de genes silenciados epigenéticamente inhibiendo la metilación del ADN. Actualmente, la 5-azacitidina y 5-azadeoxicitidina son medicamentos inhibidores de la metilación ampliamente investigados y aprobados por la FDA que se utilizan en pacientes con síndrome mielodisplásico, así como también en pacientes con leucemia mielocítica crónica $(54,55)$.

La metilación alterada de la región promotora de diversos genes se plantea como una de las razones por las que los tumores desarrollan resistencia a determinadas terapias antineoplásicas. Una de las ventajas de la terapia epigenética en los tumores colorrectales es que se encuentran hipermetilados varios genes simultáneamente, por lo que este tipo de tratamientos con medicamentos desmetilantes podrían actuar simultáneamente en diversos genes. Adicionalmente, el efecto de la terapia epigenética se podría predecir de manera anticipada, mediante el análisis de genes hipermetilados directamente en el tumor empleando plataformas de secuenciación masiva en paralelo que están disponibles actualmente $(54,55)$.

De acuerdo con lo anteriormente descrito, se ha observado que los pacientes con CCR que presentan el gen MLH1 hipermetilado y, a su vez, la MSI son resistentes a la terapia con 5-fluorouracilo (5-FU) (53); por esta razón, a dichos pacientes se les debe suministrar otro tipo de quimioterapia. De esta manera, se resalta la importancia de determinar el estado de metilación del MLH1 en los pacientes con CCR, porque orienta no solo en la elección de la terapia más adecuada, sino también en el tipo de cirugía que requieren los pacientes.

Adicionalmente, por medio de modelos celulares in vitro, se probó la hipótesis de que con la desmetilación de la región promotora de MLH1 en líneas celulares de CCR se podría restablecer la sensibilidad al tratamiento con 5-FU. Para comprobar esta hipótesis se utilizaron líneas celulares de CCR como SW48 (MLH1 metilado), HCT116 y HCT116 +chr2 (MLH1 mutado), y una línea celular HCT116 +chr3 (MLH1 normal). Se observó que el tratamiento con 5-azacitidina (5-AZA) induce la desmetilación del gen MLH1 $y$, por consiguiente, el restablecimiento de la expresión del gen y del ARN mensajero (ARNm) en las células SW48.
Asimismo, el tratamiento con 5-FU solo reduce el crecimiento celular en la línea HCT $116+\mathrm{chr} 3$, y fue menos efectivo en las demás líneas celulares (56). Estas observaciones corroboran lo establecido en cuanto a que la resistencia al 5-FU puede contrarrestarse mediante el restablecimiento de la expresión del gen MLH1 por el tratamiento con 5-AZA (56). Estos hallazgos tienen un gran impacto para el desarrollo de nuevas terapias epigenéticas antineoplásicas.

Finalmente, el avance de las nuevas tecnologías genómicas masivas permitirá analizar todo el epigenoma con el fin de lograr una mejor caracterización epigenética de los tumores colorrectales, así como también de la utilidad clínica en la búsqueda de nuevos biomarcadores epigenéticos para la detección temprana del CCR.

\section{Agradecimientos}

Este artículo lo financió la Universidad de Antioquia, convocatoria programática 2012-2013; proyecto Genética Médica CPT-1231.

\section{REFERENCIAS}

1. Ferlay J, Soerjomataram I, Dikshit Ret al. Cancer incidence and mortality worldwide: sources, methods and major patterns in GLOBOCAN 2012. Int J Cancer. 2015;136(5):E359-86. https://doi.org/10.1002/ijc.29210.

2. Siegel R, Ward E, Brawley O, et al. Cancer statistics, 2011: the impact of eliminating socioeconomic and racial disparities on premature cancer deaths. CA Cancer J Clin. 2011;61(4):212-36. https://doi.org/10.3322/caac.20121.

3. Center MM,Jemal A, Ward E. International trends in colorectal cancer incidence rates. Cancer Epidemiol Biomarkers Prev. 2009;18(6):1688-94. https://doi.org/10.1158/10559965.EPI-09-0090.

4. Center MM, Jemal A, Smith RA, et al. Worldwide variations in colorectal cancer. CA Cancer J Clin. 2009;59(6):366-78. https://doi.org/10.3322/caac.20038.

5. Piñeros M, Hernández G, Bray F. Increasing mortality rates of common malignancies in Colombia: an emerging problem. Cancer. 2004;101(10):2285-92. https://doi. org/10.1002/cncr.20607.

6. Cortés A, Bravo L, García L, et al. Incidencia, mortalidad y supervivencia por cáncer colorrectal en Cali, Colombia, 1962-2012. Salud Publica Mex. 2014;56(5):457-64. https://doi.org/10.21149/spm.v56i5.7371.

7. Migliore L, Migheli F, Spisni R, et al. Genetics, cytogenetics, and epigenetics of colorectal cancer. J Biomed Biotechnol. 2011;2011:792362. https://doi.org/10.1155/2011/792362.

8. Pavicic W, Nieminen TT, Gylling A, et al. Promoter-specific alterations of APC are a rare cause for mutation-negative familial adenomatous polyposis. Genes Chromosomes Cancer. 2014;53(10):857-64. https://doi.org/10.1002/gcc.22197. 
9. Seguí N, Guinó E, Pineda M, et al. Longer telomeres are associated with cancer risk in MMR-proficient hereditary nonpolyposis colorectal cancer. PLoS One. 2014;9(2):e86063. https://doi.org/10.1371/journal.pone.0086063.

10. Goel A, Boland CR. Epigenetics of colorectal cancer. Gastroenterology. 2012;143(6):1442-1460.e1. https://doi. org/10.1053/j.gastro.2012.09.032.

11. Fearon ER, Vogelstein B. A genetic model for colorectal tumorigenesis. Cell. 1990;61(5):759-67. https://doi. org/10.1016/0092-8674(90)90186-I.

12. Jass JR. Classification of colorectal cancer based on correlation of clinical, morphological and molecular features. Histopathology. 2007;50(1):113-30. https://doi. org/10.1111/j.1365-2559.2006.02549.x.

13. Markowitz SD, Bertagnolli MM. Molecular origins of cancer: Molecular basis of colorectal cancer. N Engl J Med. 2009;361(25):2449-60. https://doi.org/10.1056/ NEJMra0804588.

14. Duthie SJ. Folate and cancer: how DNA damage, repair and methylation impact on colon carcinogenesis. J Inherit Metab Dis. 2011;34(1):101-9. https://doi.org/10.1007/ s10545-010-9128-0.

15. Antelo M, Balaguer F, Shia J, et al. A high degree of LINE-1 hypomethylation is a unique feature of early-onset colorectal cancer. PLoS One. 2012;7(9):e45357. https://doi. org/10.1371/journal.pone.0045357.

16. Cancer Genome Atlas Network. Comprehensive molecular characterization of human colon and rectal cancer. Nature. 2012;487(7407):330-7. https://doi.org/10.1038/ nature 11252 .

17. De Carvalho DD, Sharma S, You JS, et al. DNA methylation screening identifies driver epigenetic events of cancer cell survival. Cancer Cell. 2012;21(5):655-67. https://doi. org/10.1016/j.ccr.2012.03.045.

18. Zhang L, Liu Z, Ma W, et al. The landscape of histone acetylation involved in epithelial-mesenchymal transition in lung cancer. J Cancer Res Ther. 2013;9 Suppl 2:S86-91. https:// doi.org/10.4103/0973-1482.119113.

19. Mathews LA, Crea F, Farrar WL. Epigenetic gene regulation in stem cells and correlation to cancer. Differentiation. 2009;78(1):1-17. https://doi.org/10.1016/j.diff.2009.04.002.

20. Liu Y, Hong Y, Zhao Y, et al. Histone H3 (lys-9) deacetylation is associated with transcriptional silencing of E-cadherin in colorectal cancer cell lines. Cancer Invest. 2008;26(6):57582. https://doi.org/10.1080/07357900701837168.

21. Li YX, Lu Y, Li CY, et al. Role of CDH1 promoter methylation in colorectal carcinogenesis: a meta-analysis. DNA Cell Biol. 2014;33(7):455-62. https://doi.org/10.1089/ dna.2013.2291.

22. Gardiner-Garden M, Frommer M. CpG islands in vertebrate genomes. J Mol Biol. 1987;196(2):261-82. https://doi. org/10.1016/0022-2836(87)90689-9.

23. Sandoval J, Peiró-Chova L, Pallardó FV, et al. Epigenetic biomarkers in laboratory diagnostics: emerging approaches and opportunities. Expert Rev Mol Diagn. 2013;13(5):45771. https://doi.org/10.1586/erm.13.37.
24. Meehan RR, Lewis JD, Bird AP. Characterization of $\mathrm{MeCP} 2$, a vertebrate DNA binding protein with affinity for methylated DNA. Nucleic Acids Res. 1992;20(19):508592. https://doi.org/10.1093/nar/20.19.5085.

25. Free A, Wakefield RI, Smith BO, et al. DNA recognition by the methyl-CpG binding domain of MeCP2. J Biol Chem. 2001;276(5):3353-60. https://doi.org/10.1074/ jbc.M007224200.

26. Migheli F, Migliore L. Epigenetics of colorectal cancer. Clin Genet. 2012;81(4):312-8. https://doi.org/10.1111/ j.1399-0004.2011.01829.x.

27. Carmona FJ, Esteller M. DNA methylation in early neoplasia. Cancer Biomark. 2010;9(1-6):101-11. https://doi. org/10.3233/CBM-2011-0184.

28. Choong MK, Tsafnat G. Genetic and epigenetic biomarkers of colorectal cancer. Clin Gastroenterol Hepatol. 2012;10(1):915. https://doi.org/10.1016/j.cgh.2011.04.020.

29. van Engeland M, Derks S, Smits KM, et al. Colorectal cancer epigenetics: complex simplicity. J Clin Oncol. 2011;29(10):138291. https://doi.org/10.1200/JCO.2010.28.2319.

30. Gonzalez-Gomez P, Bello MJ, Alonso ME, et al. CpG island methylation status and mutation analysis of the $\mathrm{RB} 1$ gene essential promoter region and protein-binding pocket domain in nervous system tumours. Br J Cancer. 2003;88(1):109-14. https://doi.org/10.1038/sj.bjc.6600737.

31. Roy S, Majumdar AP. Cancer stem cells in colorectal cancer: genetic and epigenetic changes. J Stem Cell Res Ther. 2012;Suppl 7(6). pii: 10342.

32. Li X, Yao X, Wang Y, et al. MLH1 promoter methylation frequency in colorectal cancer patients and related clinicopathological and molecular features. PLoS One. 2013;8(3):e59064. https://doi.org/10.1371/journal.pone.0059064.

33. Yu H, Li H, Cui Y, et al. The mRNA level of MLH1 in peripheral blood is a biomarker for the diagnosis of hereditary nonpolyposis colorectal cancer. Am J Cancer Res. 2016;6(5):1135-40.

34. Shima K, Morikawa T, Baba Y, et al. MGMT promoter methylation, loss of expression and prognosis in 855 colorectal cancers. Cancer Causes Control. 2011;22(2):301-9. https://doi.org/10.1007/s10552-010-9698-z.

35. Wheeler JM, Kim HC, Efstathiou JA, et al. Hypermethylation of the promoter region of the E-cadherin gene $(\mathrm{CDH} 1)$ in sporadic and ulcerative colitis associated colorectal cancer. Gut. 2001;48(3):367-71. https://doi.org/10.1136/gut.48.3.367.

36. Xing X, Cai W, Shi H, et al. The prognostic value of CDKN2A hypermethylation in colorectal cancer: a meta-analysis. $\mathrm{Br} \mathrm{J}$ Cancer. 2013;108(12):2542-8. https://doi.org/10.1038/ bjc. 2013.251 .

37. Soong R, Shah N, Peh BK, et al. The expression of RUNX3 in colorectal cancer is associated with disease stage and patient outcome. Br J Cancer. 2009;100(5):676-9. https:// doi.org/10.1038/sj.bjc.6604899.

38. Goel A, Arnold CN, Tassone P, et al. Epigenetic inactivation of RUNX3 in microsatellite unstable sporadic colon cancers. Int J Cancer. 2004;112(5):754-9. https://doi.org/10.1002/ ijc. 20472. 
39. Sinha R, Hussain S, Mehrotra R, et al. Kras gene mutation and RASSF1A, FHIT and MGMT gene promoter hypermethylation: indicators of tumor staging and metastasis in adenocarcinomatous sporadic colorectal cancer in Indian population. PLoS One. 2013;8(4):e60142. https://doi. org/10.1371/journal.pone.0060142.

40. Nilsson TK, Löf-Öhlin ZM, Sun XF. DNA methylation of the p14ARF, RASSF1A and APC1A genes as an independent prognostic factor in colorectal cancer patients. Int J Oncol. 2013;42(1):127-33. https://doi.org/10.3892/ ijo.2012.1682.

41. Javierre BM, Fernandez AF, Richter J, et al. Changes in the pattern of DNA methylation associate with twin discordance in systemic lupus erythematosus. Genome Res. 2010;20(2):170-9. https://doi.org/10.1101/gr.100289.109.

42. Esteller M, Corn PG, Baylin SB, et al. A gene hypermethylation profile of human cancer. Cancer Res. 2001;61(8):3225-9.

43. Warren JD, Xiong W, Bunker AM, et al. Septin 9 methylated DNA is a sensitive and specific blood test for colorectal cancer. BMC Med. 2011;9:133. https://doi. org/10.1186/1741-7015-9-133.

44. Tóth K, Sipos F, Kalmár A, et al. Detection of methylated SEPT9 in plasma is a reliable screening method for both left- and right-sided colon cancers. PLoS One. 2012;7(9):e46000. https://doi.org/10.1371/journal. pone. 0046000 .

45. deVos T, Tetzner R, Model F, et al. Circulating methylated SEPT9 DNA in plasma is a biomarker for colorectal cancer. Clin Chem. 2009;55(7):1337-46. https://doi. org/10.1373/clinchem.2008.115808.

46. Lee BB, Lee EJ, Jung EH, et al. Aberrant methylation of APC, MGMT, RASSF2A, and Wif-1 genes in plasma as a biomarker for early detection of colorectal cancer. Clin Cancer Res. 2009;15(19):6185-91. https://doi. org/10.1158/1078-0432.CCR-09-0111.
47. Schnekenburger M, Diederich M. Epigenetics Offer New Horizons for Colorectal Cancer Prevention. Curr Colorectal Cancer Rep. 2012;8(1):66-81. https://doi.org/10.1007/ s11888-011-0116-z.

48. Toyota M, Ahuja N, Ohe-Toyota M, et al. CpG island methylator phenotype in colorectal cancer. Proc Natl Acad Sci U S A. 1999;96(15):8681-6. https://doi.org/10.1073/ pnas.96.15.8681.

49. Toyota M, Ho C, Ahuja N, et al. Identification of differentially methylated sequences in colorectal cancer by methylated CpG island amplification. Cancer Res. 1999;59(10):2307-12.

50. Toyota M, Ohe-Toyota M, Ahuja N, et al. Distinct genetic profiles in colorectal tumors with or without the $\mathrm{CpG}$ island methylator phenotype. Proc Natl Acad Sci U S A. 2000;97(2):710-5. https://doi.org/10.1073/pnas.97.2.710.

51. Bardhan K, Liu K. Epigenetics and colorectal cancer pathogenesis. Cancers (Basel). 2013;5(2):676-713. https://doi. org/10.3390/cancers5020676.

52. Ang PW,Loh M, Liem N, et al. Comprehensive profiling of DNA methylation in colorectal cancer reveals subgroups with distinct clinicopathological and molecular features. BMC Cancer. 2010;10:227. https://doi.org/10.1186/1471-2407-10-227.

53. Boland CR, Shin SK, GoelA. Promoter methylation in the genesis of gastrointestinal cancer. Yonsei Med J. 2009;50(3):30921. https://doi.org/10.3349/ymj.2009.50.3.309.

54. Yan W, Guo M. Epigenetics of colorectal cancer. Methods Mol Biol. 2015;1238:405-24. https://doi.org/10.1007/9781-4939-1804-1_22.

55. Vaiopoulos AG, Athanasoula KCh, Papavassiliou AG. Epigenetic modifications in colorectal cancer: molecular insights and therapeutic challenges. Biochim Biophys Acta. 2014;1842(7):971-80. https://doi.org/10.1016/j.bbadis.2014.02.006.

56. Arnold CN, Goel A, Boland CR. Role of hMLH1 promoter hypermethylation in drug resistance to 5-fluorouracil in colorectal cancer cell lines. Int J Cancer. 2003;106(1):66-73. https://doi.org/10.1002/ijc.11176. 